\title{
Landslide forecasting and factors influencing predictability
}

\author{
Emanuele Intrieri and Giovanni Gigli \\ Department of Earth Sciences, University of Studies of Firenze, via La Pira 4, 50121 Florence, Italy \\ Correspondence to: Emanuele Intrieri (emanuele.intrieri@unifi.it)
}

Received: 20 June 2016 - Published in Nat. Hazards Earth Syst. Sci. Discuss.: 28 June 2016

Revised: 22 September 2016 - Accepted: 31 October 2016 - Published: 30 November 2016

\begin{abstract}
Forecasting a catastrophic collapse is a key element in landslide risk reduction, but it is also a very difficult task owing to the scientific difficulties in predicting a complex natural event and also to the severe social repercussions caused by a false or missed alarm. A prediction is always affected by a certain error; however, when this error can imply evacuations or other severe consequences a high reliability in the forecast is, at least, desirable.

In order to increase the confidence of predictions, a new methodology is presented here. In contrast to traditional approaches, this methodology iteratively applies several forecasting methods based on displacement data and, thanks to an innovative data representation, gives a valuation of the reliability of the prediction. This approach has been employed to back-analyse 15 landslide collapses. By introducing a predictability index, this study also contributes to the understanding of how geology and other factors influence the possibility of forecasting a slope failure. The results showed how kinematics, and all the factors influencing it, such as geomechanics, rainfall and other external agents, are key concerning landslide predictability.
\end{abstract}

\section{Introduction}

Natural disaster forecasting for early warning purposes is a field of study that drew the media attention after events such as the 26 December 2004 tsunami of Sumatra. Predicting landslides, with respect to other natural hazards, is a complex task due to the influence of many factors, such as geomechanical properties, rainfall, ground saturation, topography, earthquakes and many others. So far, few empirical landslide forecasting methods exist (Azimi et al., 1988; Fukuzono, 1985a; Mufundirwa et al., 2010; Saito, 1969; Voight et al., 1988) and none furnish a reliability degree of the prediction, mak- ing them unsuitable for decision making. In particular, when mentioning geomechanics, the reference is to the study of landslide behaviour concerning its deformation in relation to the applied stress and with special reference to its postrupture conditions.

In the present paper, research on an approach to perform probabilistic forecasting of landslide collapse is presented. This has been achieved by reiterating several predictions using more forecasting methods at the same time for multiple time series. This approach may have important applications for civil protection purposes since it provides the decision makers with a level of confidence about the prediction. Furthermore, this study, performed on 15 different case studies, shows how the possibility of forecasting the time of collapse of a landslide is affected by geomechanical or geomorphological features as much as by circumstantial conditions.

\subsection{The inverse velocity forecasting method}

Forecasting activity can be considered the fulcrum of early warning systems (Intrieri et al., 2013), i.e. cost-effective tools for mitigating risk by moving the elements at risk. For many natural phenomena forecasting is common practice (for example for hurricanes; Willoughby et al., 2007), while for others it is presently impossible (earthquakes; Jordan et al., 2011). Landslides lie in the middle of this spectrum. Their prediction can be performed through rainfall thresholds (Baum and Godt, 2010), but a more reliable approach should make use of direct measures of potential instability, such as displacements (Lacasse and Nadim, 2009; Blikra, 2008). A first issue is that only a small percentage of landslides in the world are appropriately monitored. Often monitoring is carried out for short periods not encompassing the final prefailure stages, or monitoring may be carried out with a toolow temporal frequency that does not permit following the displacement trend. This also causes an insufficient knowl- 
edge of the geomechanical processes leading to failure (here meant as the collapse following a sudden acceleration, either a first movement or a reactivation), which is also responsible for our deficiencies in predicting landslides.

In spite of this, few empirical methods for predicting the time of failure based on movement monitoring data have been developed (Azimi et al., 1988; Fukuzono, 1985a; Mufundirwa et al., 2010; Saito, 1969) and further investigated on a physical basis (Voight et al., 1988). They are all based on the hypothesis that if a landslide follows a peculiar timedependant geomechanical behaviour (called creep; Dusseault and Fordham, 1994), it will display a hyperbolic acceleration of displacements before failure; by extrapolating this trend from a displacement time series through empirical arguments, it is possible to obtain the predicted time of failure. However, such methods do not always produce good results. In fact, other than the limitation of working only with creep behaviour, sometimes the tertiary creep can evolve so rapidly that a sufficient lead time for evacuation is simply not possible (IEEIRP, 2015). In other cases natural or instrumental noise can hamper the predictions and require postprocessing to allow for effective warnings (more details on the types and effects of noise can be found in Carlà et al., 2016). Other authors also contributed to methodologies for exploiting and optimizing the classic forecasting methods (Crosta and Agliardi, 2003; Dick et al., 2015; Manconi and Giordan, 2015).

One of the most famous methods is Fukuzono's (1985a), which derives from Saito's (1969), from here on simply called the F and S method respectively. The F method requires that during the acceleration typical of the final stage of the creep (tertiary creep), the inverse of displacement velocity $\left(v^{-1}\right)$ decreases with time. The collapse is forecasted to occur when the extrapolated line reaches the abscissa axis (corresponding to a theoretical infinite velocity). Such a line may either be convex, straight or concave (Fukuzono, 1985a). When it is straight this phenomenon is sometimes referred to as the Saito effect (Petley et al., 2008).

The possibility of finding landslides showing the Saito effect has been related to the mechanical properties of the sliding mass. However, there is no general consensus on this issue.

According to some authors (Petley, 2004; Petley et al., 2002), in order to display the Saito effect, landslides need to display a brittle behaviour (which indicates a drop from peak strength to residual strength value, deformation that is concentrated along a well-defined shear surface, sudden movements and catastrophic failure, usually associated with crack formation in strong rocks). Furthermore, only brittle, intact rocks evolve in catastrophic landslides and can therefore be predicted for others (Rose and Hungr, 2007). In contrast, landslides displaying the Saito effect must have ductile failures in order to be forecasted (i.e. slower, indefinite deformation along a shear zone and under constant stress, typical of sliding on pre-existing surfaces of soft rocks) because brit- tleness is characterized by sudden, impossible to anticipate ruptures.

This complex subject is made even more difficult due to the influence of external factors (rainfall, earthquakes, excavations), structural constraints (joints, faults, contact with different lithologies) and sometimes unknown elements within the mass (the conditions of the shear surface, the history of the landslide, the presence of rock bridges). Therefore, it is often hard to establish the mechanical behaviour and even harder to find an exact correlation between the mechanical behaviour of a landslide and the possibility of predicting its failure.

\subsection{The concept of predictability}

Before assessing the influence of geomechanics on the predictability of a landslide it is first necessary to address the concept of predictability.

In literature (Azimi et al., 1988; Hutchinson, 2001; Mufundirwa et al., 2010; Rose and Hungr, 2007) there are papers that deal with "predictions" made retrospectively, that is thorough post-event analyses showing the signs of a critical pre-collapse acceleration. However, whether such signs would have been unambiguous or would have granted a sufficient lead time is often neglected.

Conversely, in this research an operational definition of predictability is considered (integrating that of an earlier warning system; UNISDR, 2009) as the feature possessed by a landslide that allows one to forecast its collapse with reasonable confidence and sufficiently in advance. This permits the dispatch of meaningful warning information to enable individuals, communities and organizations threatened by the hazard to prepare and act appropriately to reduce the possibility of harm or loss. Therefore, displaying the Saito effect is not the only prerequisite for an operational prediction. There is also the need for repeated time of failure forecasts fluctuating around a constant time value that are placed not too close together in the future. This has been achieved through the reiterative approach and the graphical representation described in the following paragraph. Finally, a semi-quantitative parameter called "prediction index" is defined in order to address the success of the predictions.

\section{Methods}

The usual way to apply landslide forecasting methods based on displacements is to obtain a single predicted time of failure $\left(t_{\mathrm{f}}\right)$ and to update such a prediction as soon as new data are gathered (Rose and Hungr, 2007). This is a deterministic approach since the real time of failure $\left(T_{\mathrm{f}}\right)$ is predicted through a single inference. Even if sometimes more predictions are made together with new data, usually only one (the most recent) is used. 
Conversely, in order to account for the uncertainty of the methods and complexity of the phenomena, predictions should have a certain confidence. Confidence may be quantitatively assessed by using the standard deviation of the forecasts $t_{\mathrm{f}}$ as a proxy. In fact, the standard deviation furnishes the dispersion (i.e. the precision) of the predictions, which may be used to calculate a time window within which the collapse is more likely to occur. Therefore, the lower the standard deviation of a set of forecasts, the higher their reliability and confidence would be. This is especially important for operative early warning systems. This probabilistic approach is achieved by reiterating the equations from Saito (1969), Fukuzono (1985a) and Mufundirwa et al. (2010) (the latter method will be called the M method from here on) for finding $t_{\mathrm{f}}$, using continuously new data and enabling the calculation of the standard deviation.

The predictions are plotted against the time when they were made (time of prediction, $t_{\mathrm{p}}$ ). We call these diagrams prediction plots (Fig. 1). A prediction is considered reliable when the inferences oscillate around the same $t_{\mathrm{f}}$. Figure 1 also shows that since reliable predictions usually display an oscillatory trend, the most updated one is not necessarily the most accurate, contrary to what is usually believed (Rose and Hungr, 2007). In fact, the length of the dataset is more important, from which $T_{\mathrm{f}}$ can be estimated through simple statistical analyses (like mean and standard deviation).

Since a single forecasting method can fail to give satisfactory results in some cases, in order to improve the confidence in the predictions even more, a multi-model approach together with the probabilistic approach is adopted. In fact, according to the diversity prediction theorem (Page, 2007; Hong and Page, 2008), diversity in predictive models reduces collective error. The highest confidence, of course, is reached when all the employed methods independently converge towards the same result.

On the other hand, confidence may also be considered as a qualitative increase in the awareness of the decision makers that can estimate the time of failure of a landslide by evaluating a large set of different predictions and their dispersions.

For this research the results from the S, F and M methods were confronted. The equations used for the iteration are obtained from the respective authors and are

$t_{\mathrm{r}}=\frac{t_{2}^{2}-\left(t_{1} \cdot t_{3}\right)}{2 t_{2}-\left(t_{1}+t_{3}\right)}$

for $\mathrm{S}$ method, where $t_{1}, t_{2}, t_{3}$ are times taken so that the displacement occurring between $t_{1}$ and $t_{2}$ is the same as between $t_{2}$ and $t_{3}$.

$t_{\mathrm{r}}=\frac{t_{2} \frac{1}{v_{1}}-t_{1} \frac{1}{v_{2}}}{\frac{1}{v_{1}}-\frac{1}{v_{2}}}$

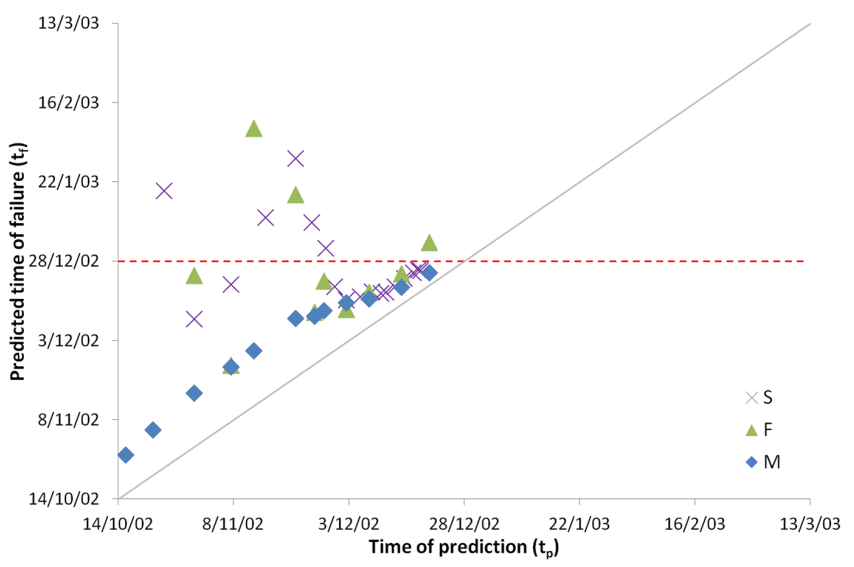

Figure 1. This graph represents probabilistic predictions performed with three different forecasting methods (Fukuzono, 1985a; Mufundirwa et al., 2010; Saito, 1969) applied to the MB34-35' displacement time series of the Mount Beni landslide (Gigli et al., 2011). The horizontal dashed line indicates the observed time of failure $\left(T_{\mathrm{f}}\right)$ and the grey diagonal line indicates the equality between $t_{\mathrm{f}}$ and $t_{\mathrm{p}}$. Therefore, the vertical distance between a point and the dashed line indicates the prediction error. The vertical distance between the diagonal line and a prediction above it is the life expectancy of the landslide at the time of prediction. In this case the predictions obtained through the $\mathrm{S}$ and $\mathrm{F}$ methods give a good estimation of $T_{\mathrm{f}}$, while the one from Mufundirwa et al. (2010) consistently forecasts the collapse a few days ahead.

for $\mathrm{F}$ method, where $v_{1}$ and $v_{2}$ are the velocities at arbitrary times $t_{1}$ and $t_{2}$.

$t \frac{\mathrm{d} D}{\mathrm{~d} t}=t_{\mathrm{r}} \frac{\mathrm{d} D}{\mathrm{~d} t}-B$

for $\mathrm{M}$ method, where $D$ is the displacement and $t_{r}$ is the angular coefficient of the line represented in a $t \frac{\mathrm{d} D}{\mathrm{~d} t}=f\left(\frac{\mathrm{d} D}{\mathrm{~d} t}\right)$ space having $B$ as the intercept. For the purposes of this paper $t_{r}$ expressed in all of these equations is equivalent to $t_{\mathrm{f}}$.

The proposed procedure consists of iteratively calculating the time of failure $t_{\mathrm{f}}$ by using the aforementioned methods and repeating the calculation as soon as new monitoring data are available. All the forecasts are recorded together with the time when they are made in order to create a time series of $t_{\mathrm{f}}=f(t)$. This can be represented in a prediction plot having $t_{\mathrm{f}}$ and $t$ (the time when the prediction is made) as coordinates. Finally, from the distribution of the forecasts within time it is possible to assess the time of failure.

\section{Time of failure prediction}

In order to find a relation between the predictability of a failure and the geological features of the landslide, the S, F and $\mathrm{M}$ methods were applied to a number of different real case studies. Some geological features of interest relative to such cases, when they were known or applicable, are reported in 


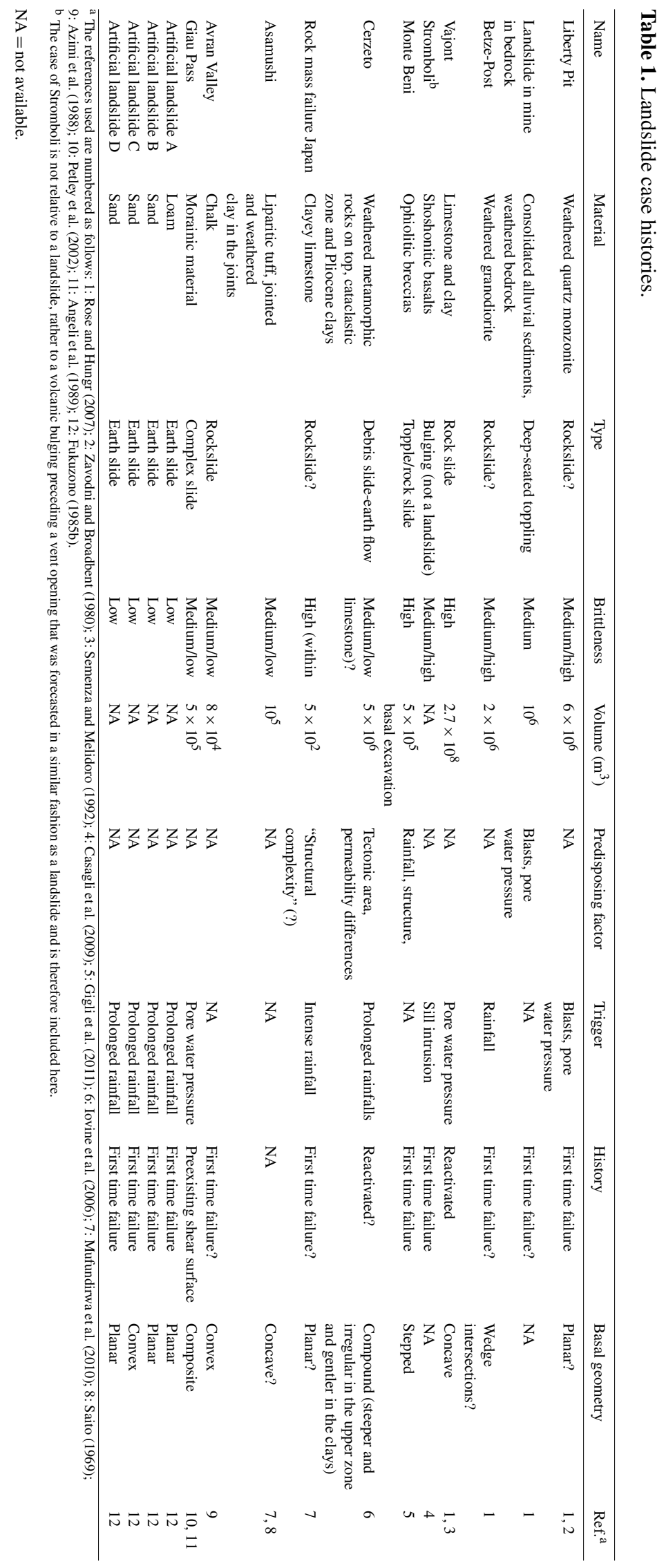



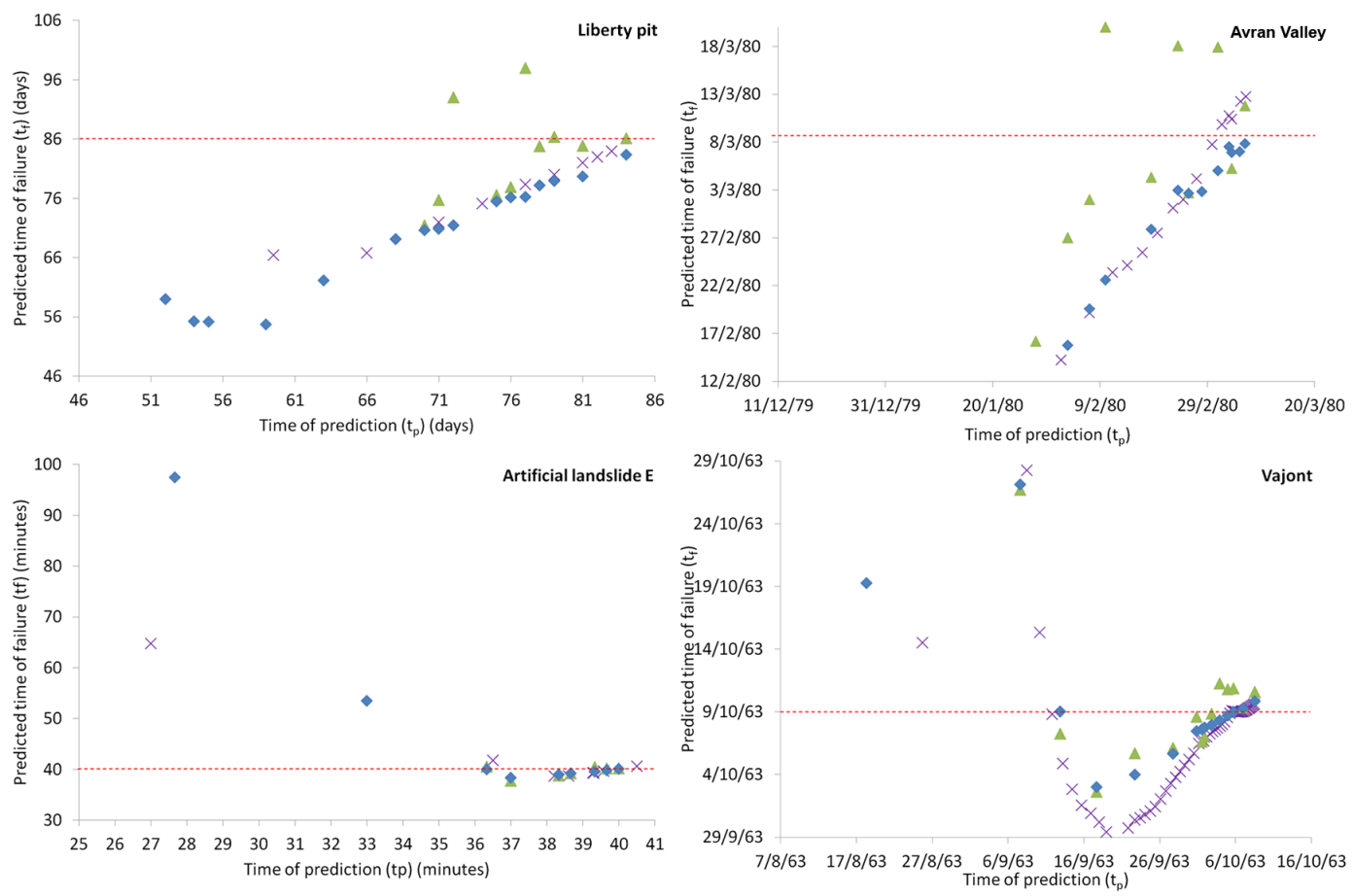

Figure 2. Prediction plots of four different case studies. The dashed line indicates $T_{\mathrm{f}}$. The crosses represent forecasts performed with the $\mathrm{S}$ method, the triangles with the F method and the diamonds with the M method. Note that F forecasts for Avran Valley landslide include other less accurate values not shown in the graph since they are out of scale.

Table 1. Concerning brittleness, since it was rarely explicitly stated in the referenced articles, it was assessed based on information such as the type of material, the presence of a reactivated landslide, the weathering and the shape of the displacement time series. Since this lead to approximations, brittleness has been evaluated using broad and qualitative definitions.

Since $T_{\mathrm{f}}$ must be known in order to assess the quality of predictions, all the case studies are from past landslides that have already failed. Therefore, the respective time of failures are all known a posteriori.

A few representative examples of prediction plots are shown in Figs. 1 and 2. The Mount Beni landslide was a $500000 \mathrm{~m}^{3}$ topple that evolved as a rockslide (Gigli et al., 2011). It was developed on a slope that had been subject to quarrying activity. The predictions oscillate quite regularly around the observed time of failure ( $T_{\mathrm{f}}$, dashed line in Fig. 2$)$. It is this convergence that permits the correct forecast of the collapse a priori since at least late November, i.e. a month before the failure; whereas, a single forecast would not be able to give a confidence of the prediction. The three methods are similar to the point that $\mathrm{S}$ and $\mathrm{F}$ previsions can be partially overlapped. M previsions overlap as well but only in the final part. The $\mathrm{M}$ method alone would not be sufficient for spreading a reliable alarm since the single forecasts do not converge but move forward to a different time of failure as the time passes by.
Similar behaviours can also be observed for the cases in Fig. 2 that display landslides with a different array of geological features (as seen in Table 1). The best results are obtained when the forecasts oscillate around $T_{\mathrm{f}}$ with sufficient time in advance (as for Vajont and, limited to the F method, for Liberty Pit), or when they consistently give the similar $t_{\mathrm{f}}$ (as for the artificial landslide E, where the terms "artificial landslide" indicates a landslide recreated in laboratory with an artificial slope). In other cases (Avran Valley and, limited to the $\mathrm{S}$ and $\mathrm{M}$ method, for Liberty Pit) the predictions are too scattered or simply never converge toward a single result, thus making it impossible to foresee a reliable time of failure.

Considering only the results of the $\mathrm{S}$ method in the case of the Avran Valley landslide, the forecasts had notably been constantly furnishing a time of failure preceding the actual $T_{\mathrm{f}}$ since the end of September. Although this may be considered a case of safe predictions (that is an error not producing a false positive and therefore not dangerous for the elements at risk), this also means that at every forecast made $t_{\mathrm{f}}$ is postponed. Given a series of ever-increasing values of $t_{\mathrm{f}}$, it is impossible to assess which of them (if any) can be assumed as a good estimate of the actual time of failure. However, since the time series of predictions is long enough, past forecasts (before early September) furnish values of $t_{\mathrm{f}}$ that, if considered together with the late ones, centre the value of $T_{\mathrm{f}}$. Therefore, it is clear how a prediction plot might allow 
decision makers to make more aware evaluations of the time of collapse of a landslide.

The results of the prediction plots can be roughly summarized by reporting the mean and standard deviation of the forecasts for each method (Fig. 3).

\section{Predictability index}

In order to evaluate the performance of the S, F and $\mathrm{M}$ methods and to relate it to the characteristics of the reported examples, an arbitrary scoring system has been implemented and attributed to each prediction plot (considering that every time series has a prediction plot for each forecasting method and that for some case studies more than one time series was available). This permits the quantification of the predictability of a collapse based on the prediction plot. A score from 1 to 5 has been assigned according to the following criteria:

- 1 point: the prediction plot never converges on a single $t_{\mathrm{f}}$ (typically $t_{\mathrm{f}}$ increases at every new datum available).

- 2 points: the predictions vary considerably at every new iteration. An average time of failure $\left(\overline{\boldsymbol{t}}_{\mathrm{f}}\right)$ can be extracted but with high uncertainty.

- 3 points: the predictions oscillate around $T_{\mathrm{f}}$, although with a certain variance.

- 4 points: the predictions have a low variance, although $\overline{\boldsymbol{t}}_{\mathrm{f}}$ is slightly different than $T_{\mathrm{f}}$. Note that when the variance was low, $\overline{\boldsymbol{t}}_{\mathrm{f}}$ and $T_{\mathrm{f}}$ never differed greatly.

- 5 points: the prediction plot is clearly centred on $T_{\mathrm{f}}$; therefore, the reliability of $\overline{\boldsymbol{t}}_{\mathrm{f}}$ is high.

By summing the scores obtained from the S, F and M prediction for each time series, what we call the Predictability Index (PI) is obtained (Table 2). Since PI is a means of evaluating the overall quality of a set of predictions (it requires observing the time series of $t_{\mathrm{f}}$ and confronting it with $T_{\mathrm{f}}$ ) and also of comparing the performance of different forecasting methods with different case studies, naturally it can only be estimated after the collapse.

By using three forecasting methods, PI ranges from 3 (impossible to predict the time of failure) to 15 (the time of failure can be predicted in advance and with a high reliability). Though a certain degree of subjectivity is unavoidable when assigning the scores, what matters here is the relative difference of PI between the case studies. In such a way it is possible to understand in which conditions a landslide is more or less predictable.

\section{Discussion}

Table 2 shows how the most predictable events (PI $>8$ ) can display very different features and are quite irrespective of the shape of the inverse velocity plot, the volume, the brittleness of the material, the history of the landslide and so on (see also Table 1).

A comparison of Fig. 3 and Table 2 illustrates how the mean and standard deviation of the forecasts alone are not enough to represent the quality of predictions and, consequently, the predictability of a landslide. In fact, the importance of a single forecast strongly depends on the time when it is made; for example, given the same set of forecasts $\left(t_{\mathrm{f}, i}\right)$, a higher PI is obtained if the first predictions done are the farthest from $T_{\mathrm{f}}$, while the final ones tend to converge to it. In this way the prediction plot assumes an oscillatory shape (like the $\mathrm{S}$ and $\mathrm{F}$ forecasts in Fig. 1). Conversely, if the same forecasts are made with a different order so that they get closer and closer to $T_{\mathrm{f}}$ as time passes by (that is $\left|t_{\mathrm{f}, i}-T_{\mathrm{f}}\right|<\left|t_{\mathrm{f}, i-1}-T_{\mathrm{f}}\right|$ ), then there is no $t_{\mathrm{f}, i}$ prevailing on the others and it is not possible to define a more probable time of collapse (like the $\mathrm{M}$ forecasts in Fig. 1). However, the average and standard deviation of $t_{\mathrm{f}}$ are the same for both cases and this explains why these two statistics alone are not as informative as a prediction plot.

From Table 2 it is also possible to assess which method gives the best results. The sum of the scores for the S, F and $M$ methods is 119, 115 and 63 respectively. Overall $S$ and $F$ perform similarly, but for a specific case study their effectiveness can be very different; therefore, their results are independent and not redundant. There is no indisputable clue suggesting when the $\mathrm{F}$ method performs better than the $\mathrm{S}$ method and vice versa. Nonetheless, it appears that $S$ is negatively influenced when the displacement curve is not regularly accelerating (Liberty Pit, Stromboli), whereas for F a few aligned points in the final tract in the inverse velocity plot are sufficient for predicting the failure. However, $\mathrm{F}$ forecasts are more disturbed when displacement data are noisy since they use their derivative (velocity) as input. Eventually $\mathbf{M}$ forecasts that generally perform more poorly and rarely (i.e. artificial landslides B and C) surpass those obtained from the $\mathrm{S}$ and $\mathrm{F}$ methods.

Interestingly, different displacement time series belonging to the same landslide can display different behaviours. This is strong evidence that even though the geological features do influence the predictability of a landslide, assuming that they keep the same for the whole landslide, other factors must determine the quality of the predictions. The last column of Table 2 shows what such factors could be for each time series, for example lithology (the asymptotic trends of the cases of Avran Valley and Giau Pass can be explained as consequences of a lowly brittle material according to Petley's experiments; Petley, 2004), external forces (excavation in open pit mines, volcanic activity, rainfall), local effects (structural constraints, displacement measured relative to internal or lateral fractures not representing the general instability of the landslide), quality of data (length of the time series, frequency of the observations, level of noise, representativeness of the monitored point), etc. 


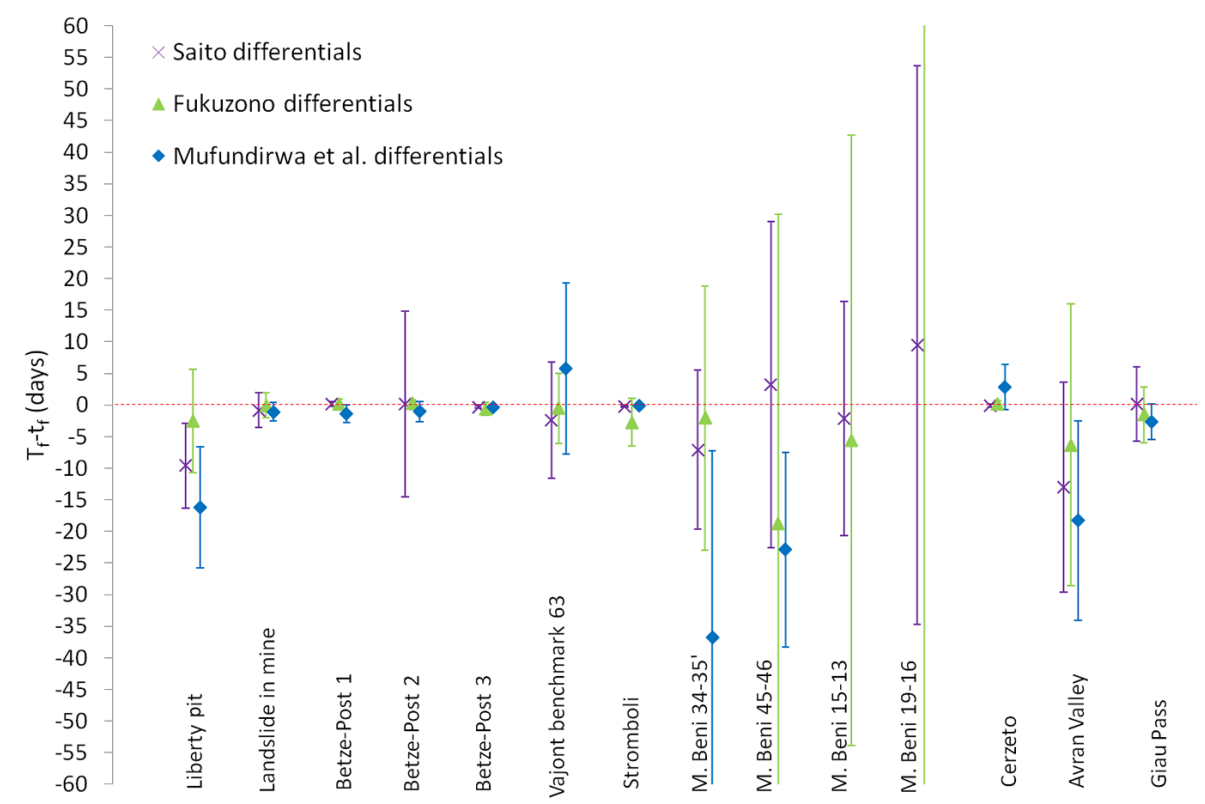

Figure 3. This graph represents for each method the differential between the mean of the forecasts $\left(\overline{\boldsymbol{t}}_{\mathrm{f}}\right)$ and the actual time of failure $\left(T_{\mathrm{f}}\right)$. Negative values are safe predictions for anticipating the time of failure. The dashed line represents exact predictions $\left(T_{\mathrm{f}}-\overline{\boldsymbol{t}}_{\mathrm{f}}=0\right)$. The standard deviations of the forecasts are represented as error bars. For the Betze-Post and Mount Beni landslides time series from different measuring points are reported. The rock mass failure, Asamushi landslide and the artificial landslides are not shown because they were monitored in a different timescale (hours or minutes).

All of these case histories show that the main factor in predictability of a landslide, and therefore in the presence of the "Saito effect", is connected to geology. However, this relation is not simple or direct. Instead, both the predictability and the "Saito effect" depend on the kinematics of the landslide, since only a landslide accelerating with a certain trend can be forecasted using the S, F and M methods. Naturally, the kinematics in turn depend on the geological conditions. In the complex relationship between geology and kinematics, the aforementioned factors may intervene. Although their interaction may not be known, its effect on displacement data can be easily measured. As a result it has been found that asymptotic trends in the inverse velocity plot have also been encountered for first failure ruptures (as found in some time series of the Mount Beni landslide), contrary to what is described by Petley (2004). This can be explained as an effect of those interactions that may alter in an unknown way the normal relationship between geology and kinematics, thus making focusing on kinematics as the key more reliable than relying on geology alone.

In fact, even though geomechanics is unquestionably a key factor, a complete geomechanical characterization is often difficult to accomplish, especially in emergency situations. Hints of a particular geomechanical behaviour are often derived from displacement data. Like in a black box model, even if the real properties of a phenomenon are not known, conclusions may be drawn from the output of those properties (i.e. the kinematics). In this case, importance has been given to kinematics because what is generally measured by monitoring are displacement data. Furthermore, many other unknown factors (rainfall, ground saturation, earthquakes, anthropic disturbance, etc.) are included in the black box model together with the geomechanics. This makes it virtually impossible to know in advance what may be the degree of influence of geomechanics alone with respect to other factors, thus leading to a focus on kinematics instead. Moreover, even though geomechanics is a key element in determining landslide predictability (because it is responsible for the creep behaviour for example), the results of the present study show that landslide prediction can be carried out with a variety of different geomechanical settings, as can also be observed by comparing Table 1 (which furnishes evaluations concerning the geomechanical properties of the case studies) with Table 2 (which states whether a collapse was predictable or not).

The prediction plots clearly show that, contrary to what is generally believed (Rose and Hungr, 2007), the last forecasts are not necessarily the most accurate and that past ones (starting from the initiation of the tertiary creep) are essential in estimating the correct time of failure. In fact, older forecasts can be more accurate and furnish precious information about the general reliability of the final prediction, as explained above. Therefore, the present study highlights the importance of considering the whole set of predictions made with time. The integration of more forecasting methods further increases reliability of the predictions, which is 
Table 2. Predictability index.

\begin{tabular}{|c|c|c|c|c|c|c|}
\hline Name & $\mathrm{S}$ & $\mathrm{F}$ & $\mathrm{M}$ & PI & Inverse velocity trend & Notes \\
\hline Liberty Pit & 1 & 5 & 1 & 7 & $\begin{array}{l}\text { Asymptotic (linear } \\
\text { at the end) }\end{array}$ & $\begin{array}{l}\text { Open pit mine, structural control } \\
\text { of two intersecting faults }\end{array}$ \\
\hline Landslide in mine & 5 & 5 & 5 & 15 & Linear & Open pit mine \\
\hline Betze-Post 1 & 3 & 3 & 1 & 7 & Linear & Open pit mine \\
\hline Betze-Post 2 & 4 & 5 & 4 & 13 & Linear & Open pit mine \\
\hline Betze-Post 3 & 5 & 4 & 1 & 10 & Linear & Open pit mine \\
\hline Vajont benchmark 63 & 5 & 5 & 5 & 15 & Linear & $\begin{array}{l}\text { Air pressure and cementation } \\
\text { caused catastrophic collapse }\end{array}$ \\
\hline Stromboli & 1 & 2 & 2 & 5 & Asymptotic & Volcanic context \\
\hline Mount Beni 12-9 & 4 & 5 & 1 & 10 & Concave & Back fracture \\
\hline Mount Beni $\mathrm{a}^{\prime} \mathrm{b}^{\prime}$ & 1 & 3 & 1 & 5 & Linear & Short time series \\
\hline Mount Beni $15-13$ & 5 & 3 & 1 & 9 & Linear & Internal fracture \\
\hline Mount Beni 34-35' & 5 & 3 & 1 & 9 & Linear & Lateral fracture, short time series \\
\hline Mount Beni 45-47 & 2 & 3 & 1 & 6 & Linear & Back fracture, short time series \\
\hline Mount Beni 3-2 & 5 & 2 & 1 & 8 & Concave & Back fracture \\
\hline Mount Beni $4^{\prime}-6$ & 1 & 4 & 1 & 6 & Linear & Back fracture, short time series \\
\hline Mount Beni 24-23 & 4 & 2 & 1 & 7 & Linear & lateral fracture \\
\hline Mount Beni 49-24 & 5 & 1 & 1 & 7 & Linear & Lateral fracture, short time series \\
\hline Mount Beni $35^{\prime}-36$ & 2 & 5 & 1 & 8 & Linear & Lateral fracture, short time series \\
\hline Mount Beni 33-35' & 3 & 3 & 1 & 7 & Linear & Lateral fracture, short time series \\
\hline Mount Beni 36-37 & 4 & 3 & 1 & 8 & Linear & Lateral fracture \\
\hline Mount Beni 19-16 & 2 & 2 & 1 & 5 & Linear & Lateral fracture \\
\hline Mount Beni 19-17 & 1 & 2 & 1 & 4 & Linear & Lateral fracture, short time series \\
\hline Mount Beni 33-34 & 4 & 2 & 1 & 7 & Linear & Internal fracture \\
\hline Mount Beni 43-44 & 3 & 2 & 1 & 6 & $\begin{array}{l}\text { Asymptotic (constant } \\
\text { velocity at the end) }\end{array}$ & $\begin{array}{l}\text { Internal fracture, } \\
\text { short time series }\end{array}$ \\
\hline Mount Beni 40-41 & 3 & 2 & 1 & 6 & $\begin{array}{l}\text { Asymptotic (constant } \\
\text { velocity at the end) }\end{array}$ & $\begin{array}{l}\text { Internal fracture, } \\
\text { short time series }\end{array}$ \\
\hline Mount Beni $40-42$ & 3 & 3 & 1 & 7 & Linear & Internal fracture, short time series \\
\hline Mount Beni 45-46 & 3 & 2 & 2 & 7 & Linear & Back fracture, short time series \\
\hline Mount Beni 1-2 & 4 & 2 & 1 & 7 & Linear & Back fracture \\
\hline Cerzeto & 5 & 5 & 1 & 11 & Linear & - \\
\hline Rock mass failure Japan & 2 & 2 & 1 & 5 & Convex & Open pit mine, very small landslide \\
\hline Asamushi & 5 & 3 & 1 & 9 & Linear & - \\
\hline Avran Valley 5 & 1 & 2 & 1 & 4 & Concave & - \\
\hline Avran Valley 6 & 1 & 1 & 1 & 3 & Asymptotic & - \\
\hline Avran Valley 7 & 1 & 2 & 1 & 4 & Concave & - \\
\hline Giau Pass & 3 & 3 & 1 & 7 & Asymptotic/concave & - \\
\hline Artificial landslide A & 5 & 5 & 5 & 15 & Convex & $40^{\circ}$ artificial slope \\
\hline Artificial landslide B & 2 & 2 & 3 & 7 & Concave & $40^{\circ}$ artificial slope \\
\hline Artificial landslide C & 1 & 2 & 3 & 6 & Linear (slightly convex) & $40^{\circ}$ artificial slope \\
\hline Artificial landslide D & 5 & 5 & 5 & 15 & Linear & $30^{\circ}$ artificial slope \\
\hline
\end{tabular}

of great importance for early warning systems, in particular when evacuations are envisaged.

Limitations of the proposed approach are those related to the intrinsic limitations of the forecasting methods that were integrated. In fact, since the S, F and M methods are all based on the creep theory, the occurrence of a tertiary creep phase slow enough to allow monitoring and taking action is necessary. Voight (1988) also assumes that there must be no external force acting on the landslide, but the examples shown in this paper demonstrate that this may not represent a limitation.

Figure 3 shows that the mean of the predictions can be used as a proxy for the time of failure, but, as stated above in this paragraph, it is also shown that the obtained accuracy may not be enough since the mean does not exploit all of the information provided by a prediction plot. Other statistical indicators have been attempted, but none of them appeared to better approximate the value of $T_{\mathrm{f}}$, mainly due to the difficulty of accounting for the important time factor in the fore- 


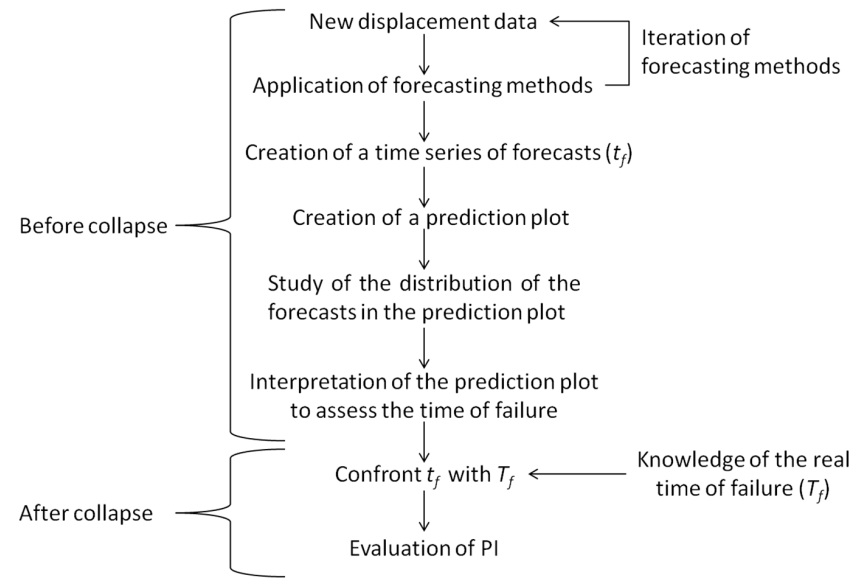

Figure 4. Flow chart that synthesizes the proposed procedure.

casts and also because not every prediction plot displays the characteristic oscillations. Therefore, the interpretation of the prediction plot (and in particular of the dispersion of the forecasts with time) represents the most valuable tool for decision makers, who, in this way, can make judgements informed by a large set of quantitative and redundant data and assess the "weight" of a single prediction by comparing it with many others.

Resuming, the proposed methodology can be summarized as in Fig. 4.

\section{Conclusions}

In conclusion, the main aspect of the proposed methodology concerns a way to produce and represent forecasting data. Then this methodology is used to assess the influence of different factors in the predictability of a landslide. The main results of the study are summarized hereafter.

Prediction plots are introduced as graphs showing the evolution of collapse forecasts with time. Such plots provide more information than simple average and standard deviation of the forecasts and improve the reliability of the final prediction.

A PI has been introduced as a scoring system based on the description of the prediction plot in order to evaluate the quality of a set of predictions.

The predictability of a landslide depends firstly on its kinematics and then on what determines it (geology, external forces, local effects, etc.).

Landslide collapses can be forecasted whether they are in highly or slightly brittle materials, rock or earth material of different types, or materials with different sliding surface geometries, volumes and triggers.

Contrary to what is generally assumed (Voight, 1988; Rose and Hungr, 2007), landslides can also be forecasted when external forces are acting on it.
The asymptotic behaviour of the inverse velocity curve does not imply that the landslide cannot be correctly forecasted, even though it can hinder the prediction.

The asymptotic behaviour may be induced by external factors, lithology and local effects, rather than only by crack propagation. In fact, asymptotic trends were found in first time failures and in both brittle and slightly brittle materials. The crack propagation explanation is not neglected, but it may not represent the general rule.

Most recent displacement monitoring data increase the confidence when estimating the time of failure but do not necessarily provide more accurate predictions than the older ones (provided that they start from after the initiation of the tertiary creep).

The developed approach integrates more forecasting methods to further improve the reliability of the prediction.

Author contributions. Emanuele Intrieri developed the idea and performed the analyses. Giovanni Gigli supervised and improved the paper.

Competing interests. The authors declare that they have no conflict of interest.

Acknowledgements. The authors are thankful to Antonio Intrieri for his important technical contribution when computing the calculations needed for this work.

Edited by: T. Bogaard

Reviewed by: three anonymous referees

\section{References}

Angeli, M.-G., Gasparetto, P., Pasuto, A., and Silvano, S.: Examples of landslide instrumentation (Italy), in: Proceedings of 12th International Conference on Soil Mechanics and Foundation Engineering, Rio de Janeiro, Brazil, 3, 1531-1534, 1989.

Azimi, C., Biarez, J., Desvarreux, P., and Keime, F.: Prévision d'éboulement en terrain gypseux, edited by: Bonnard, C. and Balkema, Å., in: Proceedings of 5th International Symposium on Landslides, Lausanne, Rotterdam, 1, 531-536, 1988.

Baum, R. L. and Godt, J. W.: Early warning of rainfall-induced shallow landslides and debris flows in the USA, Landslides, 7, 259272, 2010.

Blikra, L. H.: The Åknes rockslide: Monitoring, threshold values and early-warning, 10th International Symposium on Landslides and Engineered Slopes, 30 June-4 July, Xian, China, 1089-1094, 2008.

Carlà, T., Intrieri, E., Di Traglia, F., Nolesini, T., Gigli, G., and Casagli, N.: Guidelines on the use of inverse velocity method as a tool for setting alarm thresholds and forecasting landslides and structure collapses, Landslides, 1-18, doi:10.1007/s10346016-0731-5, 2016. 
Casagli, N., Tibaldi, A., Merri, A., Del Ventisette, C., Apuani, T., Guerri, L., Tarchi, D., Fortuny-Guasch, J., Leva, D., and Nico, G.: Deformation of Stromboli Volcano (Italy) during the 2007 crisis by radar interferometry, numerical modeling and field structural data, J. Volcanol. Geoth. Res., 182, 182-200, 2009.

Crosta, G. B. and Agliardi, F.: Failure forecast for large rock slides by surface displacement measurements, Can. Geotech. J., 40, 176-191, 2003.

Dick, G. J., Eberhaardt, E., Cabrejo-Liévano, A. G., Stead, D., and Rose, N.: Development of an early-warning time-of-failure analysis methodology for open-pit mine slopes utilizing groundbased slope stability radar monitoring data, Can. Geotech. J., 52, 515-529, 2015.

Dusseault, M. B. and Fordham, C. J.: Time-dependent behavior of rocks, Chapter 6, edited by: Hudson, J. A., Comprehensive Rock Engineering, Pergamon Press, 4, 119-149, 1994.

Fukuzono, T.: A method to predict the time of slope failure caused by rainfall using the inverse number of velocity of surface displacement, J. Jpn. Landslide Soc., 22, 8-13, 1985a.

Fukuzono, T.: A new method for predicting the failure time of a slope failure, in: Proceedings of 4th International Conference and Field Workshop on Landslides, Tokyo, Japan, 145-150, 1985 b.

Gigli, G., Fanti, R., Canuti, P., and Casagli, N.: Integration of advanced monitoring and numerical modeling techniques for the complete risk scenario analysis of rockslides: The case of Mt. Beni (Florence, Italy), Eng. Geol., 120, 48-59, 2011.

Hong, L. and Page, S. E.: Some microfoundations of collective wisdom, in: Collective Wisdom Principles and Mechanisms, edited by: Landemore, H. and Elster, J., Cambridge University Press, 392 pp., 2008.

Hutchinson, J. N.: Landslide risk - to know, to foresee, to prevent, Geol. Tec. Ambient., 9, 3-24, 2001.

IEEIRP (Independent Expert Engineering Investigation and Review Panel): Report on Mount Polley Tailings Storage Facility Breach, Province of British Columbia, 156 pp., available at: https://www. mountpolleyreviewpanel.ca (last access: November 2016), 2015.

Intrieri, E., Gigli, G., Casagli, N., and Nadim, F.: Brief communication "Landslide Early Warning System: toolbox and general concepts", Nat. Hazards Earth Syst. Sci., 13, 85-90, doi:10.5194/nhess-13-85-2013, 2013.

Iovine, G., Petrucci, O., Rizzo, V., and Tansi, C.: The March 7th 2005 Cavallerizzo (Cerzeto) landslide in Calabria - Southern Italy, in: Proceedings of 10th IAEG Congress, Nottingham, Great Britain, Geol. Soc. London, 785, 1-12, 2006.

Jordan, T., Chen, Y.-T., Gasparini, P., Madariaga, R., Main, I., Marzocchi, W., Papadopoulos, G., Sobolev, G., Yamaoka, K., and Zschau, J.: Operational Earthquake Forecasting: State of Knowledge and Guidelines for Implementation, Ann. Geophys. Italy, 54, 316-391, 2011.
Lacasse, S. and Nadim, F.: Landslide risk assessment and mitigation strategy, edited by: Sassa, K. and Canuti, P., Landslides - Disaster Risk Reduction, Springer-Verlag Berlin Heidelberg, 31-61, 2009.

Manconi, A. and Giordan, D.: Landslide early warning based on failure forecast models: the example of the Mt. de La Saxe rockslide, northern Italy, Nat. Hazards Earth Syst. Sci., 15, 16391644, doi:10.5194/nhess-15-1639-2015, 2015.

Mufundirwa, A., Fujii, Y., and Kodama, J.: A new practical method for prediction of geomechanical failure-time, Int. J. Rock Mech. Min., 47, 1079-1090, 2010.

Page, S. E.: The difference: how the power of diversity creates better groups, firms, schools, and societies, Princeton University Press, 424 pp., 2007.

Petley, D. N.: The evolution of slope failures: mechanisms of rupture propagation, Nat. Hazards Earth Syst. Sci., 4, 147-152, doi:10.5194/nhess-4-147-2004, 2004.

Petley, D. N., Bulmer, M. H., and Murphy, W.: Patterns of movement in rotational and translational landslide, Geology, 30, 719722, 2002.

Petley, D. N., Petley, D. J., and Allison, R. J.: Temporal prediction in landslides - Understanding the Saito effect, in: Proceedings of 10th International Symposium on Landslides and Engineered Slopes, Xian, China, 865-871, 2008.

Rose, N. D. and Hungr, O.: Forecasting potential rock slope failure in open pit mines using the inverse velocity method, Int. J. Rock Mech. Min., 44, 308-320, 2007.

Saito, M.: Forecasting time of slope failure by tertiary creep, in: Proceedings of 7th International Conference on Soil Mechanics and Foundations Engineering, Montreal, Canada, Pergamon Press, Oxford, Great Britain, 667-683, 1969.

Semenza, E. and Melidoro, G.: Proceedings of the meeting on the 1963 Vaiont landslide, in: Proceedings of the meeting on the 1963 Vaiont landslide, 1986, edited by: Semenza, E. and Melidoro., G., Ferrara, Italy, IAEG Italian Section, University of Ferrara, 1, 1-218, 1992.

UNISDR (United Nations International Strategy for Disaster Reduction): Terminology on Disaster Risk Reduction, 13 pp., 2007.

Voight, B. A.: Method for prediction of volcanic eruption, Nature, 332, 125-130, 1988.

Willoughby, H. E., Rappaport, E. N., and Marks, F. D.: Hurricane Forecasting: The State of the Art, Nat. Hazards Rev., 8, 45-49, 2007.

Zavodni, Z. M. and Broadbent, C. D.: Slope failure kinematics. Canadian Institute of Mining, Metal Petroleum (CIM) Bulletin, 73, 69-74, 1980. 